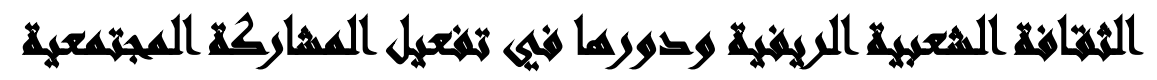

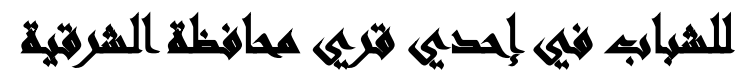

[Ir]

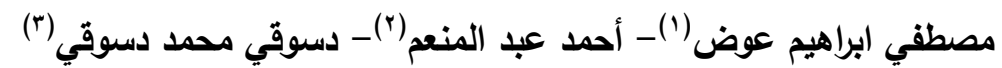

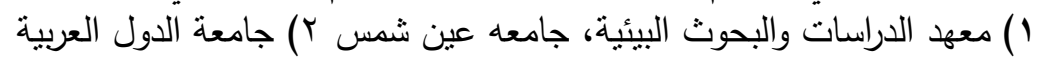

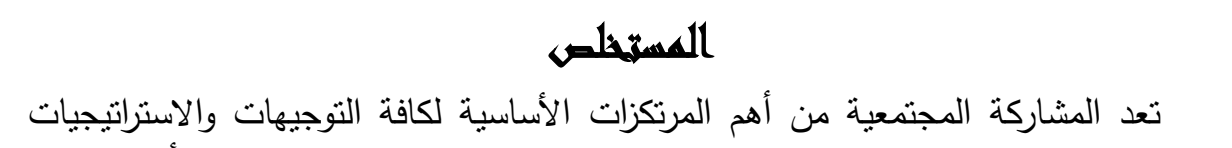

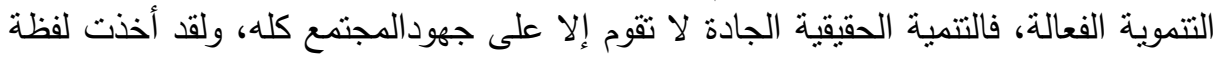

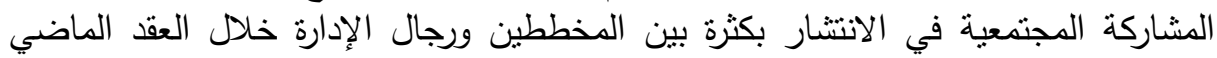

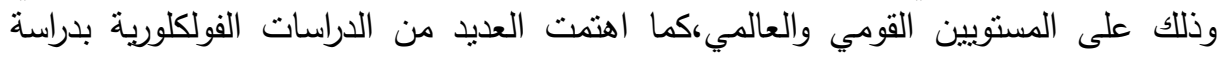

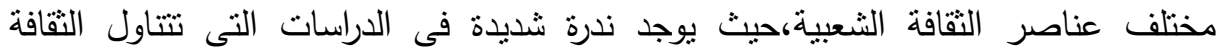

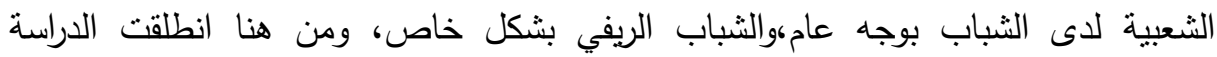

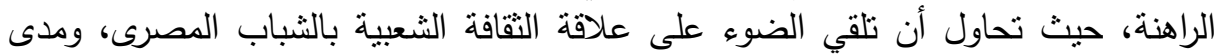

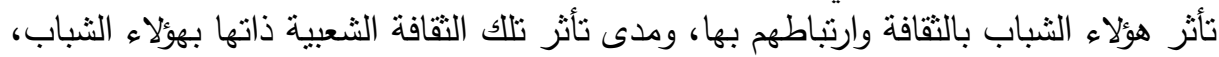
ووقع اختيار الباحثون على نظرية البنائية الوظيفية لكونها رؤية سوسيولوجية ترمي الى تلى تحليل

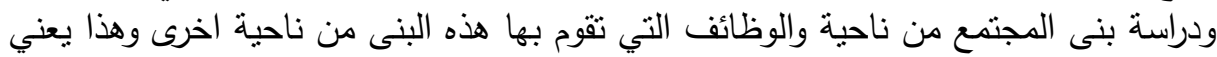

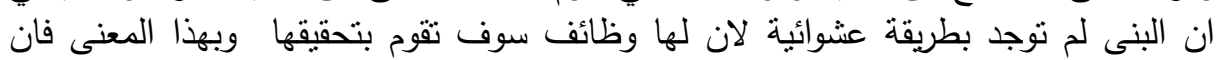

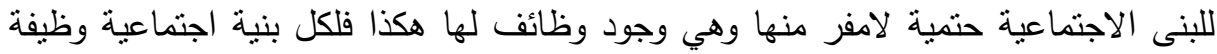

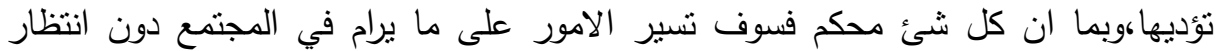

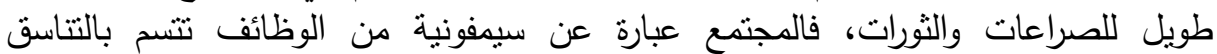

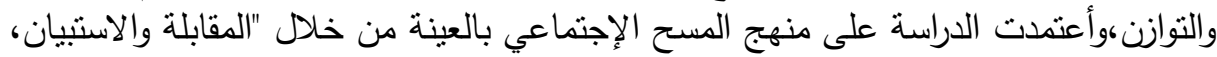
وتم اختيار العينة عن طريق العينة الطبقية (حسب الثريحة العمرية) ثم العينة العشوائية

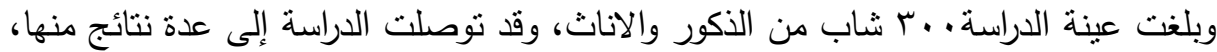

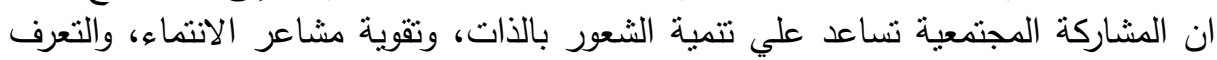

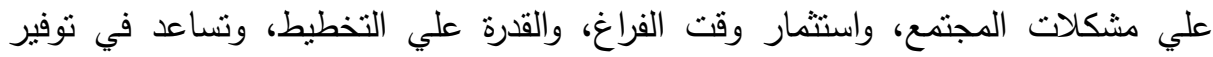

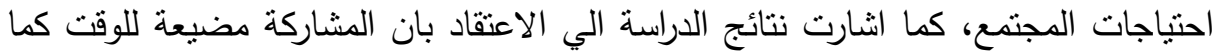

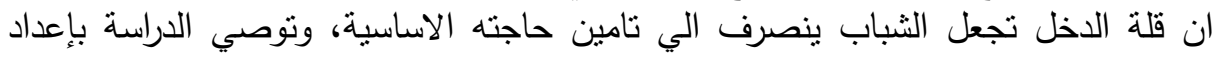

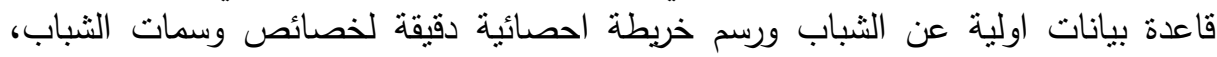

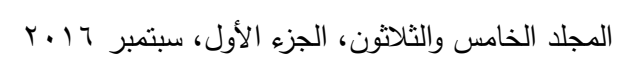


وتقديم برامج اعلامية تهدف الي توعية الثباب باهميم ومجالات وكيفية المشاركة المجتمعية الفاعلة.

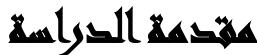

تعد الثقافة الثعبية جزء من الثقافة العامة لهذا المجتمع حيث يتم نقل الثقافة واكتسابها

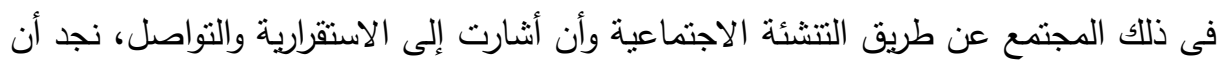

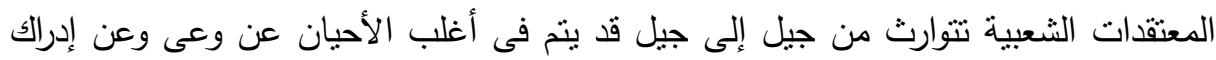

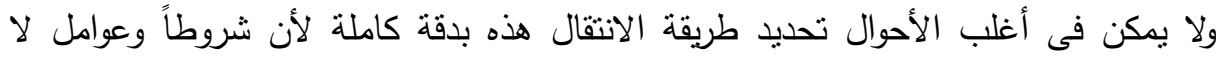

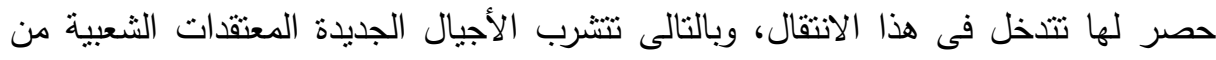
خلال عملية التتشئة الاجتماعية،ومن خلال المشاركة الفعلية فى حياة الجماعة، فالتقافة الثعبية تعبير أساسي ومعقد للمجتمع في وجوده الماضي والآني وحتى الآتي، كما أنها

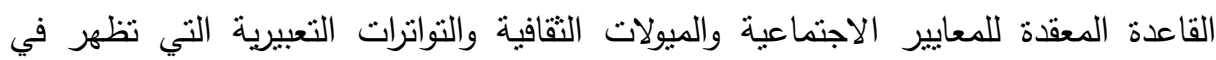
الانتاجات التي يعرف أفراد المجتمع فيها ثقافتهم ويجدون مباشرة علامات هويتهم(عزت التهات حجازي.99 (19)، لذا فان تفعيل عملية المشاركة المجتمعية وتعميقها في وعي الناس وتقافتهم

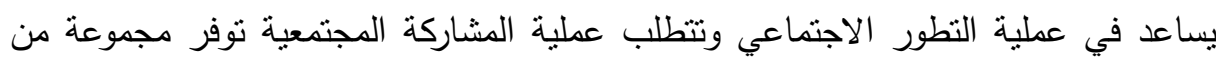

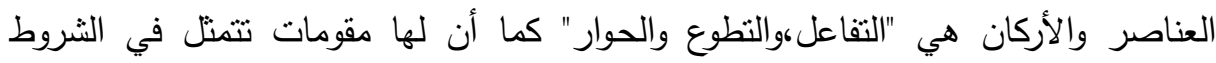
الضرورية لتحقيقها كالقيم منل التعاون والتسامح والمواطنة، ولا بد من نوفر قنوات التهات للمشاركة

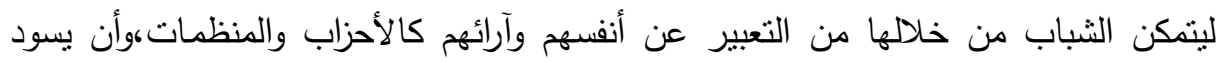
مناخ من الحرية في المجتمع لكي يندفع الثباب للمشاركة في تلك القنوات التي تتفق مع دعن مبادئهم دون خوف، فالمشاركة المجتمعية تقوم على العقلانية وتتنتر في المجتمعات التي لئي

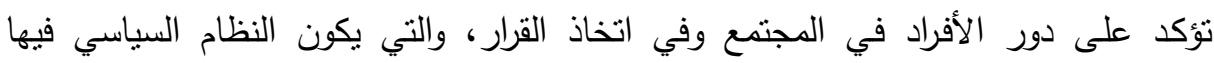

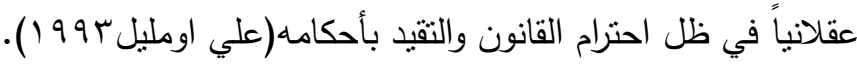




\section{هشمله القراسما}

الثقافة الثعبية تمثل كل التماثلات الجماعية للحياة المعيثية الفعلية منها والموجودة، المتمنلة في تطلعات الجماعة ورغباتها ومعتقداتها، وفي نظرتها للحياة، والتي يعبر عنها

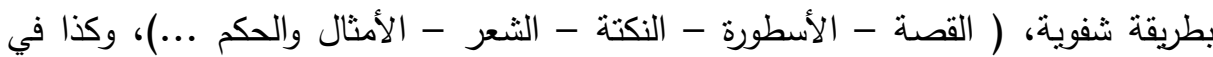
بيانات وتظاهرات سلوكية ( حفلات شعبية - رقص - طقوس - ممارسات - ولائم واجتماعات . . . ) وهذا ما يسميه البعض بالفلكلور مع اختلاف في حدة هذه التظاهرات ووظائفها داخل

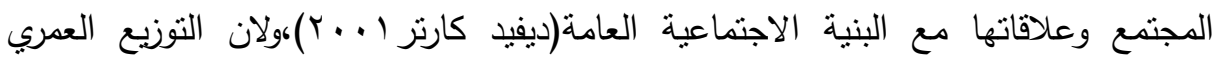

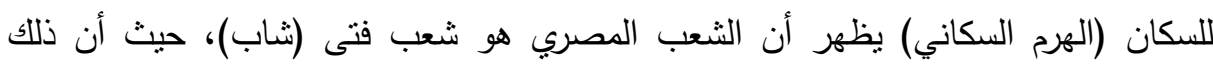

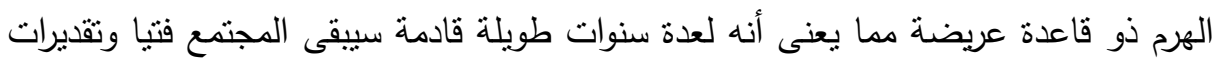
الدولة لأحوال وواقع الثباب في مصر نتشير إلى وجود ه, بr مليون نسمة من سكان البلاد

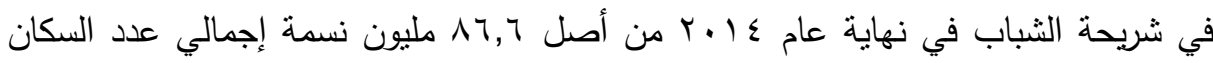

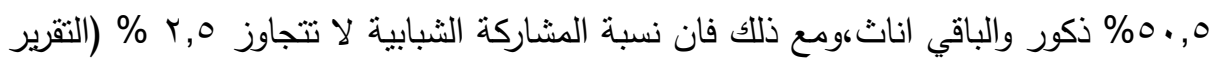

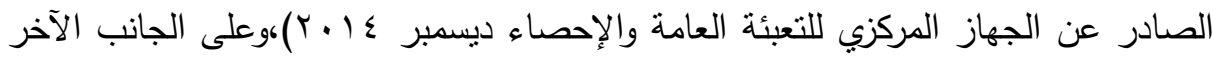

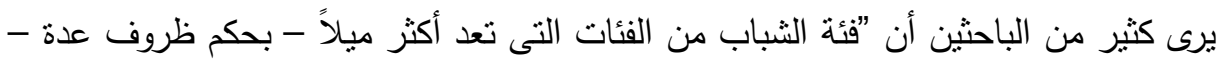

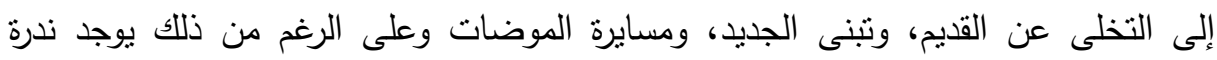

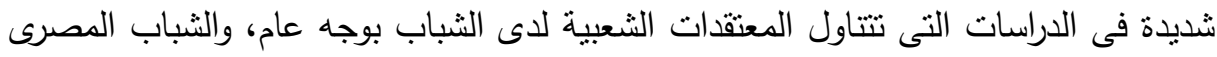

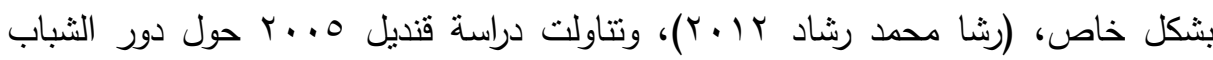
الجامعي في المشاركة لتصب في نفس الاتجاه من حيث تدني مستوي المشاركة،حيث أظهرت

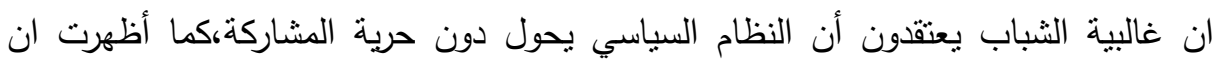

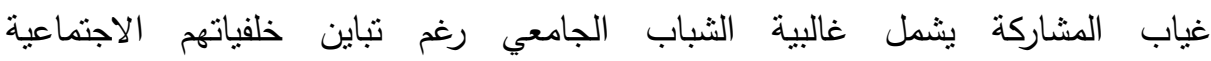

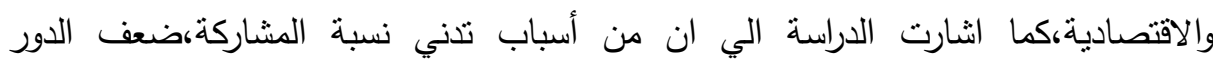

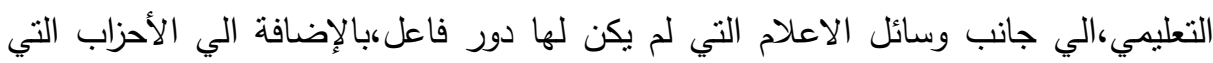

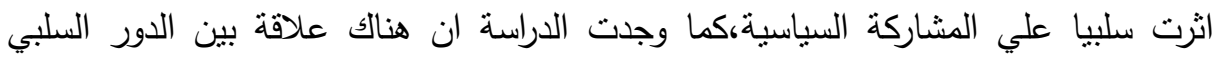
لوسائل التشئية وأزمة المشاركة وعدم الجدوى من المشاركة،ومن هنا تبلورت مشكلة الدراسة

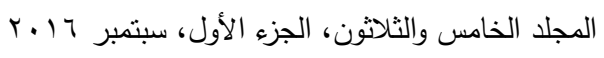


الحالية والتي يتحدد موضوعها في معرفة الدور الذي تلعبة الثقافة الثعبية في تحفيز الثباب علي المشاركة المجتمعية في الريف المصري.

\section{توساولايت التوراسما}

1- كيف تتعكس المعتقدات الثعبية على قرارات الثباب وسلوكياتهم؟

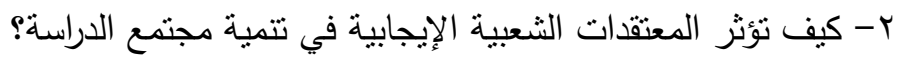

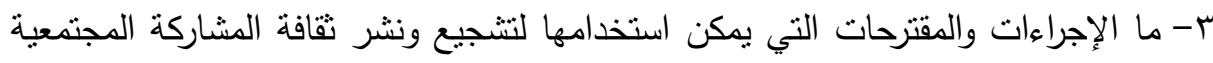

$$
\text { لدى الثباب في قرية الدراسة ؟ }
$$

\section{أهميه التوراسما}

لهذه الدراسة اهميتها الاكاديمية النظرية فضلا عن اهميتها المجتمعية التطبيقية،اذ حال اكتثاف صدق المقولات النظرية او عدمه،يعد ذلك اختبار للتوجه النظري الذي انطلقت منه

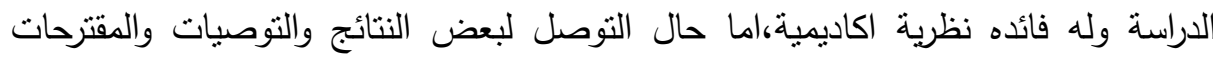
التطبيقية في مجال ثقافة المشاركة المجتمعية في القرية المصرية محدداته واثاره وما الي ذلك. تقيد هذه المقترحات في التعامل مع الثقافة الثعبية بالقرية،بل واستثمار العناصر المؤثرة في خطط التتمية وما الي ذللك. 1 - الأهمية النظرية : تتبلور أهمية الدراسة فى كونها محاولة لإثراء الدراسات الفولكلورية والأنثروبولوجية لجانب من أهم جوانب التراث الثعبى وهى المعتقدات الثعبية، وتتتاول فئة من أهم فئات المجتمع المصرى وهى فئة الثباب، التى تعانى من ندرة الدراسات التى وهى التى

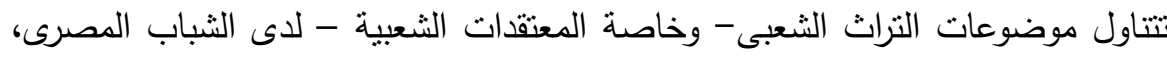
ومن أهمية هذا البحث أيضاً دراسة جوانب المعتقدات الثعبية في احدي القري المصرية بمحافظة الثرقية. 
r- الأهمية التطبيقية: باعتبار أن الثباب هم الحاضر والمستقبل وباعتبار أن أنماط التفكير لدى الإنسان تؤثر على رؤيته المستقبلية وتحديد توقعانه، ومتطلباته، واحتياجاته؛

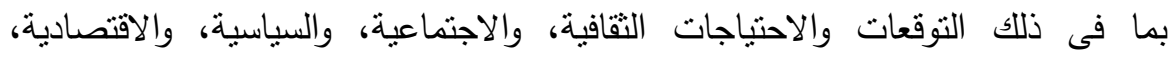

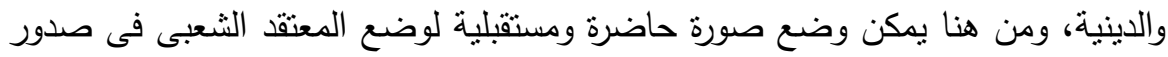

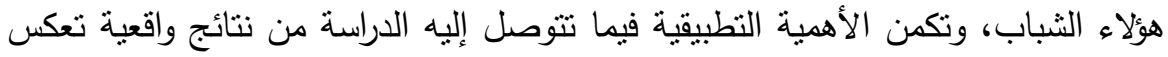

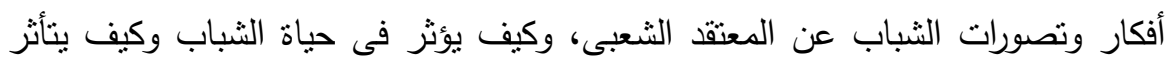

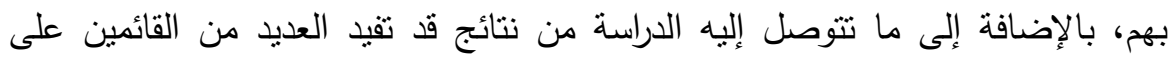

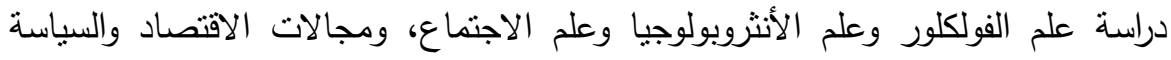

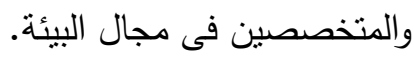

\section{أهساهث التصراسة}

\section{تهذف هذه الاراسة الى ما يلي:}

1- محاولة التعرف على طبيعة التفاعل بين مختلف عناصر المتنقدات الثتعبية والثباب

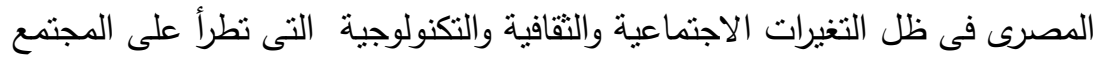
المصرى بشكل عام والثباب الريفي بشكل خاص. r- التعرف على دور الثقافة الثعبية الريفية في المشاركة المجتمعية للثباب في الريف.

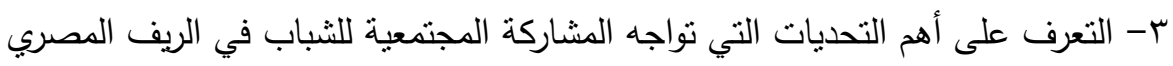

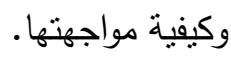

\section{مهزاهيهر التوراسة}

مفهوم الثباب: إنّ الثباب مرحلة عمرية تبدأ بنهاية سنّ المراهةة وبداية سنّ الرجولة، فهي

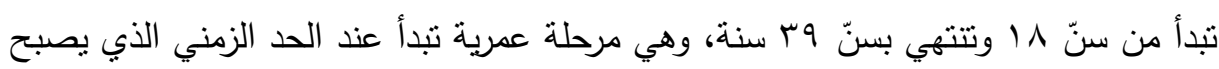

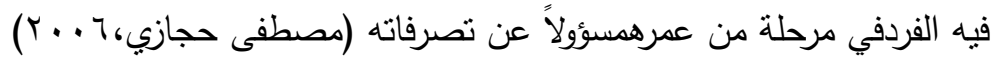




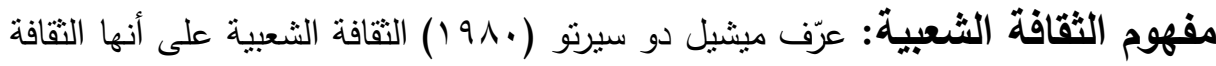
"العادية" لأناس عاديين، أي أنها ثقافة تتثكل تبعاً للواقع اليومي ومن خلال النشاطات العادية

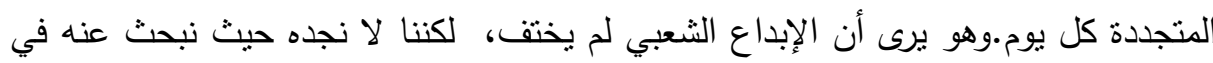
المنتجات التي يمكننا العثور عليها والمحددة بشكل واضحى الإبداع لأنها متعددة الأشكال ومبعثرة:"فهي تهرب عبر ألف درب ودرب"(محمد السويدي، (1991).

مفهوم العولمة: يقول محمد الجابري :ان العولمة هي العمل على تعميم نمط حضاري

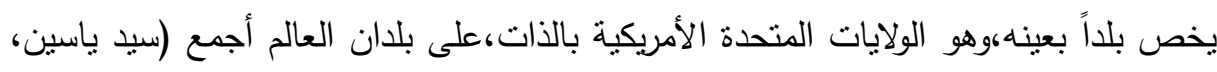

مفهوم المشاركة الشعبية: هي فعل جماعي موجه نحو النتمية المجتمعية يشارك فيه افراد المجتمع في احداث تغيرات في الحياة الاجتماعية والاقتصادية والنقافية والسياسية في المجتمع من خلا المشاركة في تحديد الاهداف والاولويات والموارد ووضع خطط العمل المناسبة

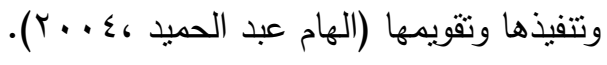

\section{الصراسايت الماريخ}

هناك العديد من الدراسات السابقة التى تتاولت المشاركة المجتمعية للشباب،وانه من خلال المشاركة سوف يتحول الثباب من متلقي سلبي الي فاعل ايجابي مبادر، ووسيط في عملية

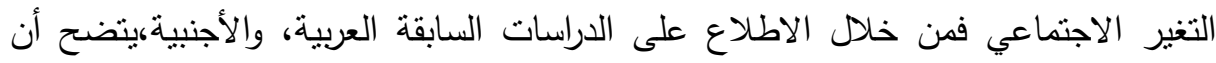
هناك الكثير من الدراسات التى تتعلق بهذه الدراسة ومنها:

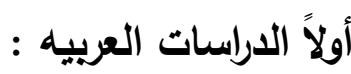
1 - دراسة (رشا محمد رشاد r r ب r): تحاول هذه الدراسة أن تلقي الضوء على علاقة

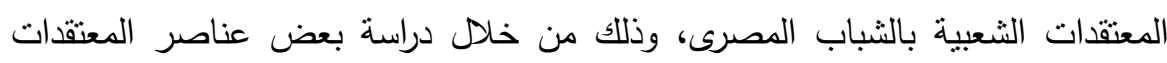

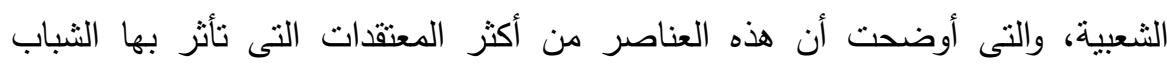

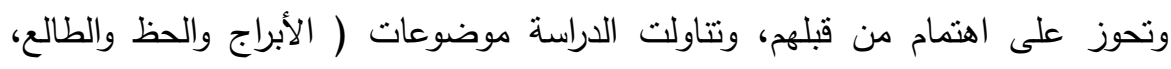

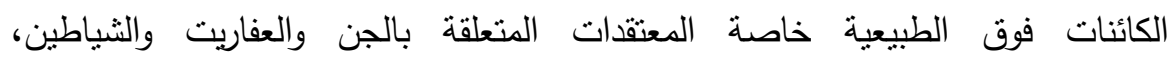


الحسد،التفاؤل والتثاؤم)، وتعرض الباحثة لروئة وسائل الإعلام ووسائل الاتصال والوسائل

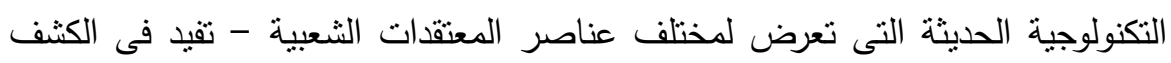
عن القيم والآراء والاتجاهات التقافية التى تسود المجتمع فى ماضيه وحاضره؛ ولذلك فإنها

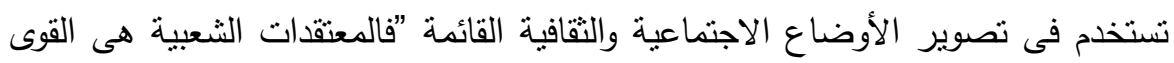

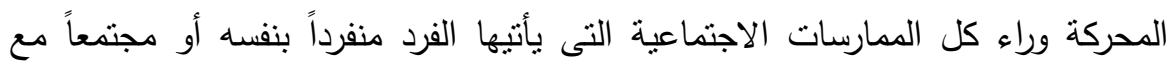

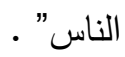

r- دراسة (ريهام جلال حجاج با • ץ): تهدف الدراسة الى دراسة علاقة برامج التتمية

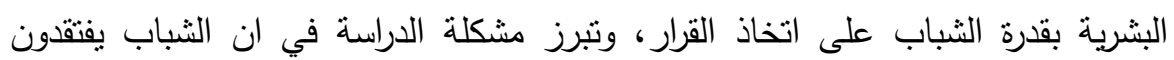

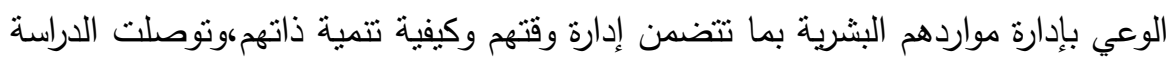

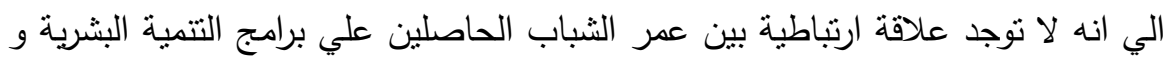

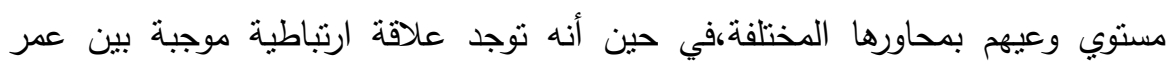

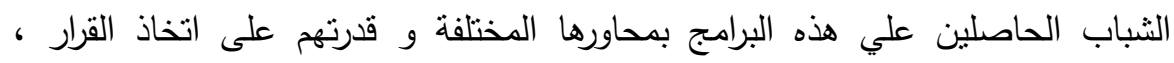
بمعنى أنه كلما زاد عمر الثاب كلما زادت قدراته على اتخاذ القرار .

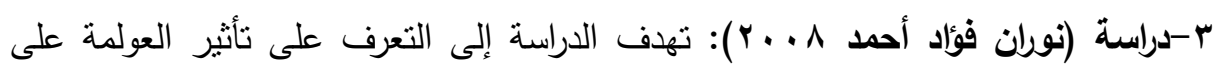
ملامح الثقافة الثعبية المصرية والتعرف على ملامح الثقافة الثعبية بالمجتمع المصري والتعرف على ثأثثر العولمة على الثقافة الثعبية المصرية والتعرف على أساليب وآليات

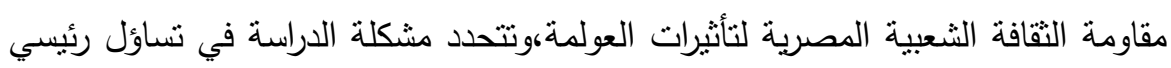
مؤداه "' ما نأثيرات العولمة على الثقافة الثعبية المصرية ، وقد اعتمدت الدراسة علي لئي الاسلوب الوصفي التحليلي بهدف جمع البيانات والحقائق التي تتعلق بالتقافة الثعبية

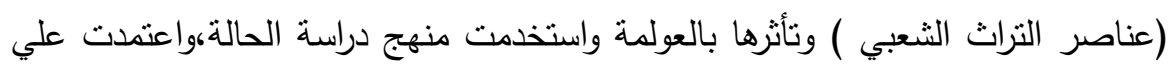

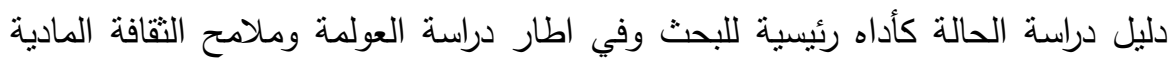

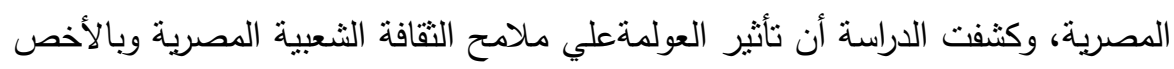
بعض عناصر التراث الثعبي ، الفخار ،السجاد ،المنتجات الخشبي. 


\section{ثانياً الدراسات الأجنبية:}

1 - دراسة (1999 Maria de Oliveira Nazara Rocca)

آليات لزيادة مشاركة الثباب النساء والرجال في التتمية الريفية، في إطار السياسة العامة

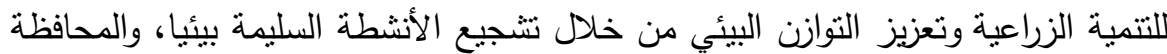
على المناظر الطبيعية الريفية التقليدية والتمويل المشترك (السياحة والترفيه، والصيد، وغيرها)، ونتجيع المزارعين على البقاء من أجل الحفاظ على سكان الريف،حيث تعاني

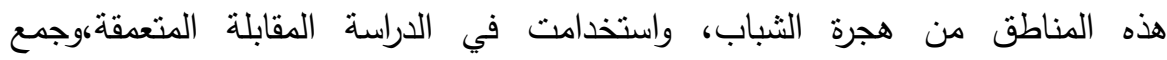
المعلومات،تحليل مجموعة مختارة من وثائق الاتحاد الأوروبي واستخدام البيانات الإحصائية والتحليلات الديموغرافية والاجتماعية والاقتصادية المتاحة من مكتب الإحصاء

$$
\text { الأوروبي، ودائرة الإحصاءات المركزية للاتحاد الأوروبي. }
$$

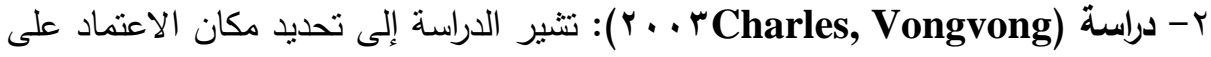
الذات في المجتمع ومفهوم تتمية المتمع أن مشاركة الناس أنفسهم في الجهود المبذولة لتحسين مستواهم الذين يعيشون فيه من خلال تقديم الخبرة الفنية والمساعدة المالية،ومساهمة المرأة والدور الأساسي الذي تلعبه في المجتمع ودور الحكومة بالتعاون مع المنظمات غير الحكومية والبحث عن حلول لمشاكل التتمية الملحة من خلال تعبئة الموارد المحلية إذا تم تعزيز هذه المؤسسات من قبل الدولة وجعلها أكثر ديمقراطية، فإنها يمكن أن تلعب دورا أكبر في التخطيط ووضع استراتيجيات لدعم هذه المبادرات المحلية،التي سوف تقطع شوطا طويلا في تحويل معظم المجتمعات الريفية،ومساهمة المجتمعات في الجهود الرامية إلى التخفيف من حدة الفقر لأنها ستحدد المشاريع ذات الأولوية التي تعمل على معايشة المجتمع بمساعدة الوكالات الدولية ذات الخبرة الفنية والمالية اللازمة،وإضفاء الطابع المؤسسي على نتمية المجتمع من خلال إنشاء إدارة

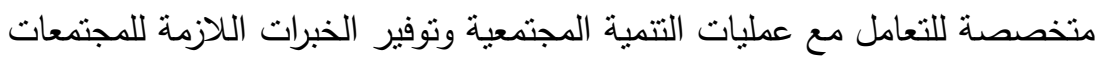


r- دراسة (2001 Laura Ward, Wayne Hey): أظهرت النتائج الى ان التوعية ستكون بمثابة همزة وصل بين مقدمي الثباب والثباب في ريتشموند لتسهيل عملية إثراك الثباب المعرضة للخطر في البرامج المجتمعية والخدمات بما في ذلك الترفيهية وألانشطة

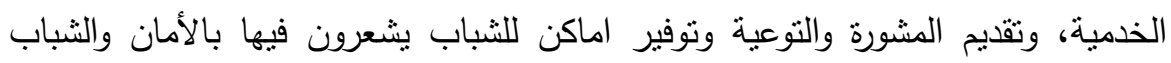
اللذين هم في خطر الانخراط في أنشطة غير مقبولة اجتماعيا لشعورهم بالملل،وتوفير الفرص والمهارات والقيم اللازمه للمعيشة الإيجابية والنشطة وإنشاء لجنان من الثباب فئه الغرض منها زياده الوعي لدى الثباب وعمل البرامج والخدمات من خلال وسائل الإعلام

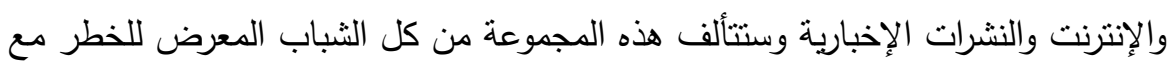
الفائدة والمهارات المطلوبة وهذه اللجان تساعد علي إنشاء موقع على شبكة الانترنت

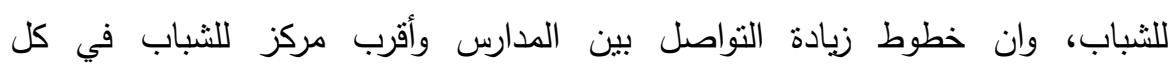
مدرسة،والذي يعرض البرامج الحالية للشباب والأحداث القادمة في المجتمع ويتم تحديث لهيث هذا المجلس أسبوعيا من قبل الطلاب على النحو المحدد، يساعد علي تعزيز المشاركة في لئي البرامج والفعاليات المجتمعية.

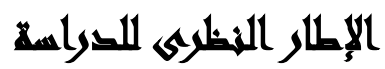

تقوم التتمية البشرية على مكونات متعددة وتعتبر المشاركة مكوناً أساسياً وضرورياً

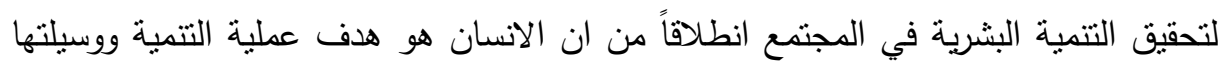
والمشاركة مفهوم واسع من الصعب الاحاطة بكل جوانبه ومجال المشاركة المجتمعية عملية

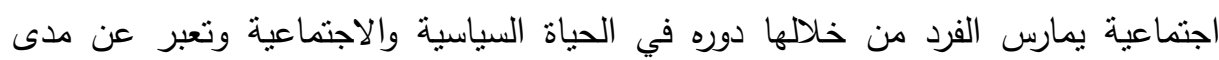
اندماج أفراد المجتمع وتفاعلهم في انشطة المجتمع بشكل طوعي وتعد فئة الثباب الثريحة

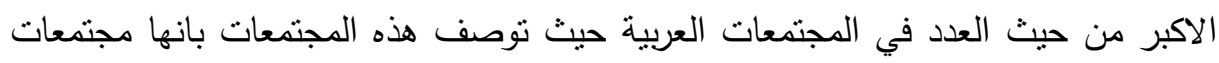
فنتية ذات هرم سكاني كبير القاعدة فعلى الثباب يقع عاتق انماء المجتمع وصناعة مستقبله لذا فان التحدي الاكبر بالنسبة لجميع الدول هو كيفية الاستفادة من طاقة هذه الثريحة

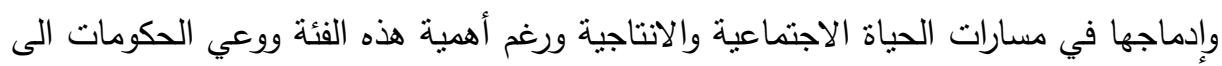

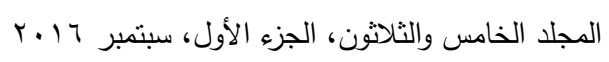


ذلك الا انها تعتبر من الفئات المجمعية المهشة حيث لاتوجد استراتيجيات وسياسات من أجل توظيف طاقات الثباب وتحقيق مشاركتهم في شؤون المجتمع ، ان قلة المراكز الثبابية والجمعيات والمنظمات غير الحكومية التي تسمح للشباب بالمشاركة فيها(علي اومليل

نظرية البنائية الوظيفية: يرى راد كليف براون أن البناء الاجتماعي ليس إلا مجموعة من

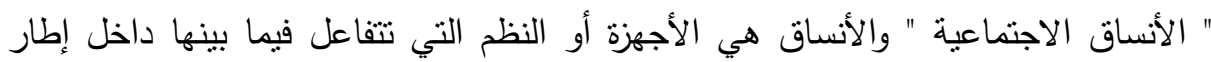
البناء الكلي الثامل والنسق عبارة عن عدد من النظم الاجتماعية التي تتشابك وتتضامن فيما

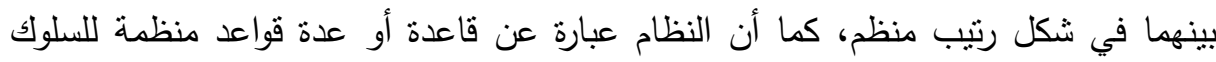
يتفق عليها الأشخاص وتتظمها الجماعة داخل البناء وتدور الفكرة الرئيسية للاتجاه الوظيفي حول وجود نسق يتكون من عدة أنظمة أو عناصر وهذه العناصر لا بد لها أن تحافظ على الى اله

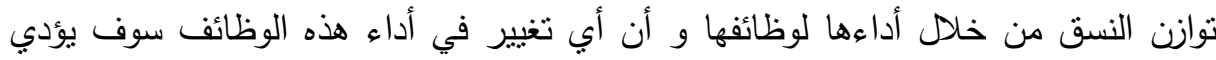
إلى اختلال نوازن النسق و نشوء المشاكل فيه وهذه الفكرة قد تكون مقبولة في لحظة معينة من

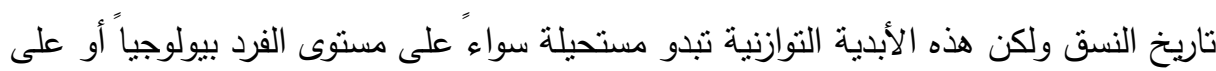

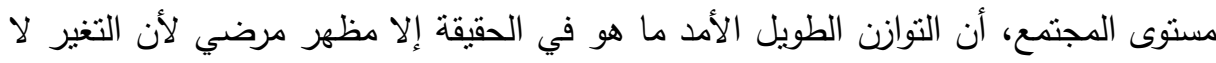

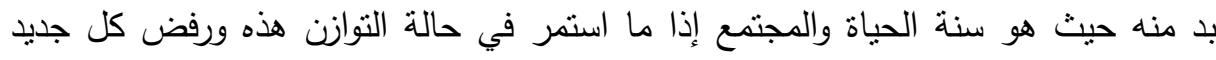

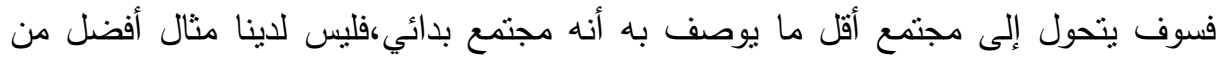

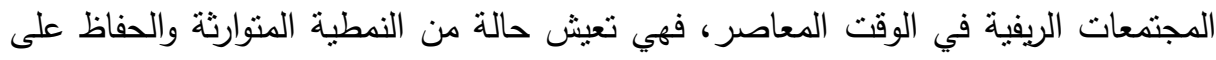

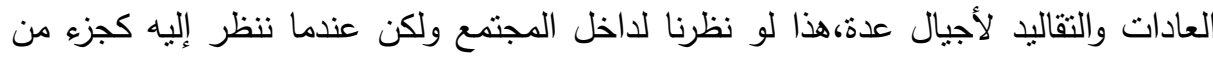
هذا العالم نرى أنه يعيش حالة مرضية هي حالة انفصال عما حوله،وبالتالي هو في الحقيقة

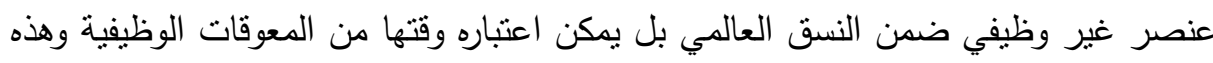

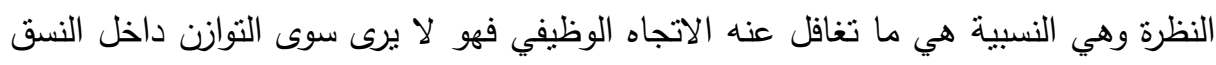

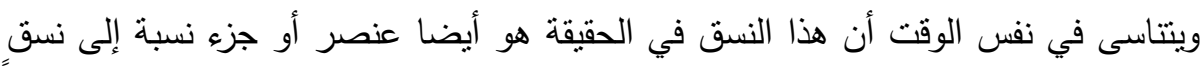

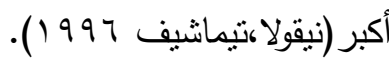


وقد تم اختيار هذه النظرية لتوجيه البحث لأنها أولا نظرية اجتماعية بحتة وموضوع

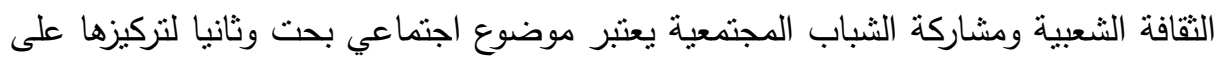
النسق والنظام والوظيفة التي هي عناصر اساسية في دراسة موضوع البحث، وتتنمي ظاهرة المشاركة المجتمعية للثباب إلى نسق التبادل ويعتبر التبادل من المواضيع النيع الأساسية في

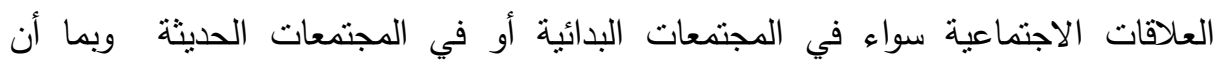
المشاركة ظاهرة من الظواهر الاجتماعية المنتشرة في جميع المجتمعات تقريبا فهي إذن مهمة لمعرفة جوانب النظام الاجتماعي في أي مجتمع وعلاقة هذا النظام بغيره من الأنظمة فالمشاركة الفاعلة تقوم بوظيفة اجتماعية هي نوطيد العلاقات الاجتماعية وتكوين الصداقات التئه وتتتمي في الوقت ذاته إلى البناء الاجتماعي الثامل في أي مجتمع فظاهرة الهدية لا يمكن دراستها منفصله عن بافي النظم الاجتماعية من سياسية ودينية واقتصادية وقرابية وغيرها (إسماعيل، زكي،محمد،ب191()، ولذلك كان تبني النظرية الوظيفية وتطبيقها على ظاهرة المشاركة المجتمعية للشباب من الخطوات المهمة في هذا البحث لأن هذه الظاهرة تمس ولنس جوانب النظرية وخاصة فيما يتعلق بتشعب العلاقات الاجتماعية ووظيفة هذه الظاهرة " المشاركة المجتمعية للشباب " في حياة الناس في أي مجتمع،ومن الجدير القول أن الاتجاه

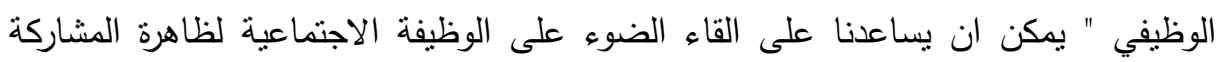

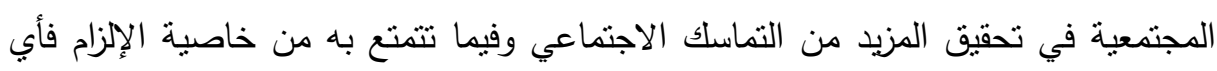

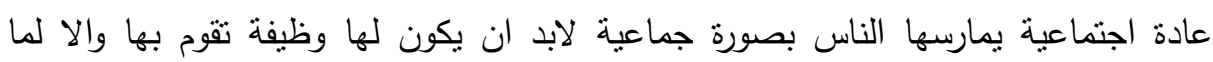
وجدت هذه الظاهرة (أحمد،سمير نعيم 910 (1).

\section{الإجبراعاهي المنهجية للتصواسمة}

أولاً: نوع الدراسة: قام الباحثون بإجراء دراسة وصفية تحليلية للشباب في احدي القري، للوقوف على الخصائص الاجتماعية والفيزيقية المرتبطة بالمشاركة المجتمعية والبيئية.

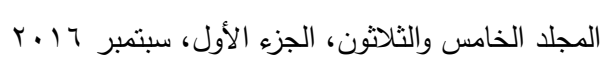




\section{ثانياً: منهج الدراسة: قام الباحثون بتطبيق المنهج الوصفي المعتدد على الأتي:}

1- طريقة المسح الاجتماعي بالعينة باستخدام الاسنبيان وذلك لاعطاء افراد العينة فرصة كافية للإجابة علي الأسئلة بدقة ودون النقيد بوقت معين من خلال الدراسة الميدانية للوقوف على الخصائص الاجتماعية والفيزيقية المرتبطة بالمشاركة المجتمعية والبيئية. r- دراسة الحالة : قام الباحثون بأعداد دراسة حالة على عدد من الثباب بقرية الدراسة،حيث قام بأختيار عدد I افراد من اهل القرية وعمل مقابلة شخصية للأجابة على الأسئلة الموجوده في أستمارة دراسة الحالة .

ثالثا: أدوات الدراسة:

* صياغة المقاييس في الصورة الأولية: حيث أطلع الباحثون على الدراسات والبحوث

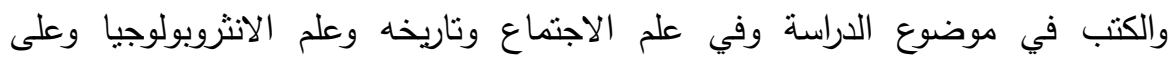

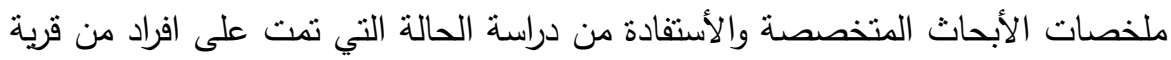
الدراسة وصياغة العبارات بصورة تتلائم مع هذه الإجابات والأطلاع على أدوات الدراسات الأخرى من مقاييس وإستبيانات وتحديد محاور كل مقياس وكذلك الإستبانة وتحديد فقرات كل محور ،وبعد الخطوات السابقة تمكن الباحثون من صياغة أدوات الدراسة والتى تتكون من بيانات عامة عن الخصائص الديموجرافية للمبحوث،ثم مقياس الخصائص الاجتماعية لثباب القرية،ومقياس الخصائص الفيزيقية لبيئة الدراسة ، ثم مقياس المشاركة المجتمعية، 1 - المقابلة استخدم الباحث المقابلة المتعمقة مع عدد 7 افراد من اهل القرية نم انتقاؤهم علي النحو الاتي (ذكر كبير امي،انثي كبيرة امية،ذكر كبير متعلم،انتي كبيرة متعلمة،شاب متعلم ،وفتاه متعلمة) لكي تمثل مستويات اجتماعية واقتصادية منباينة ولكي تمنل مهنا متباينة وذلك لجمع معلومات تقصيلية حول اثر الثقافة الثعبية علي المشاركة المجتمعية بشكل كمي لتغطية الجوانب الكمية ولقد انتمل دليل المقابلة علي عه سؤال مقسمة الي محورين وهما (الثقافة الثعبية واثرها علي الثباب، المشاركة المجتمعية للشباب ) ويهدف لهن مقياس الدراسة إلى الكثف عن الفروق بين شباب قرية الدراسة في الخصائص الاجتماعية 
والفيزيقية المحيطة بهم في بيئة الدراسة،فضلاً عن الثقافة الثخصية المكتسبة للثباب

$$
\text { ودورها في المشاركة المجتمعية. }
$$

r- استمارة الاستبيان: لقياس دور الثقافة الشعبية في تفعيل المشاركة المجتمعية للشباب،وقد استخدم الاستبيان المغلق والتي تضمن ل السؤالاً تحتوى على البيانات الأولية وتتثمل:

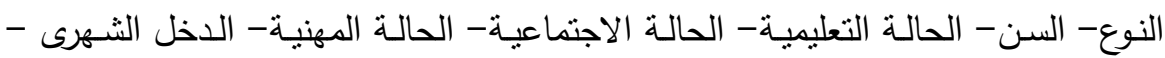
بيانات خاصة بكل من العوامل الاقتصادية والعوامل الاجتماعية.

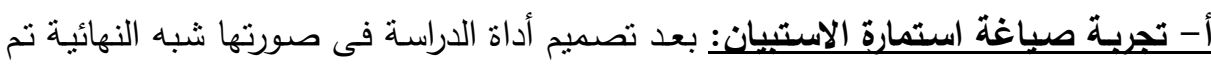
اختبارها عن طريق تطبيقها على ( . . () مائة من المبحوثين حتى يمكن اكتشاف مدى صلاحيتها وملاءمتها قبل استخدامها فى البحث.

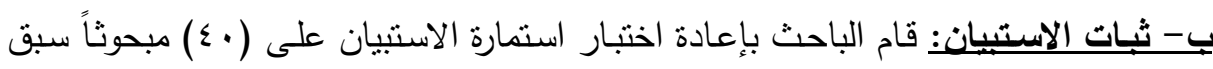

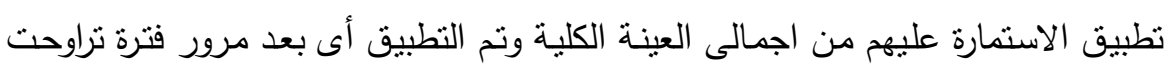
خمسة عشر يوما وتم حساب معامل الثبات باستخدام نسب الاتفاق لكل سؤال من أسئلة

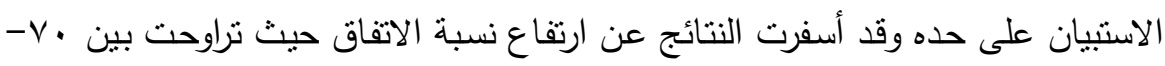

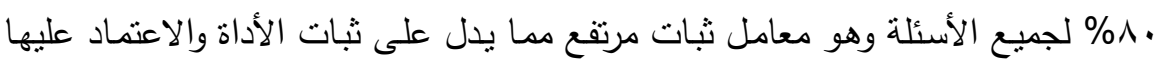

$$
\text { فى الدراسة. }
$$

$$
\text { جـــــق الاستيِيان : قد استخدم الباحث صدف الاستمارة كالتالى: }
$$

1- صدق المحكين روعى فى تصميم بنود استمارة الاستبيان أن تعكس العوامل الاقتصادية الإنفان

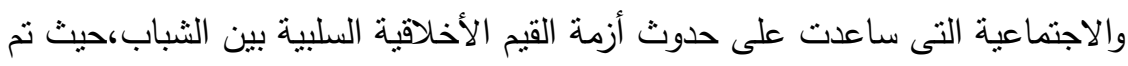
عرض المقاييس على عدد من المحكمين من أساتذة الجامعات المصرية كجامعة عين

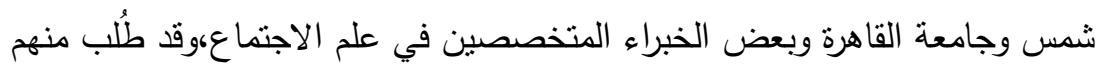
تحديد مدى مناسبة كل فقرة للمجال الذي تقبسه ومدى وضوح الفقرات لغوياً،وأخذ الباحث تعديلات المحكمين وتم تعديل المقاييس ليصبح عدد فقرتها ال فقرة فقط.

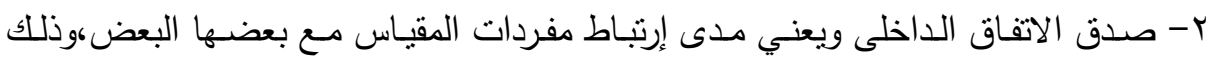
بحساب معامل إرتباط بيرسون بين كل فقرة ومجموع المقياس الذي تتتمي إليه الفقرةهـع

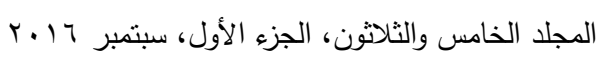


إضافة مستوى الدلالة بإستخدام معادلة بيرسون للإزتباط ومن خلال المقارنة بين إجابات

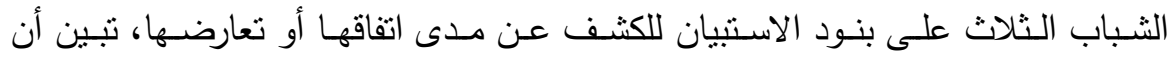
الإجابات جاءت على نحو منسق، وهذا مؤشر لصدق الاتفاق الداخلى.

\section{هجالاهيت التصاسة}

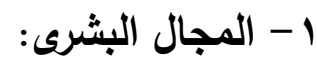

تم اختبار ( · ·r) من الثباب بقرية الدراسة (اناث وذكور ).

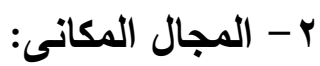

قرية طاروط - مركز الزقازيق - محافظة الثرقية .

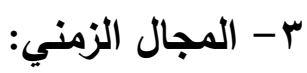

حيث أخذت الدراسة الميدانية لنطبيق المقاييس في مراحلها التطبيقية عاماً كاملاً من

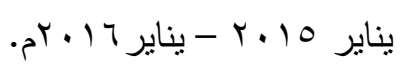

وصف نتائج البيانات الأولية لعينة الدراسة:

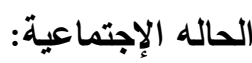
وأثارت الدراسة الي ان الغالبية اعزب بنسبة بلغت (70\%). العمر : إن منوسط أعمار العينة (Tr) سنة ،وهذا يتفق مع شروط العينة. التعليم: وجد ان التعليم المتوسط يمثل غالبية العينة بنسبة بلغت حوالي (70\%). 


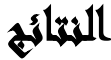

التساؤال الأول: كيف تتعكس المعتقات الثعبية على قرارات الثباب

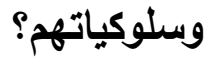

جدول(1) - (1) - المشاركة المجتمعية للشباب

\begin{tabular}{|c|c|c|c|c|c|c|}
\hline المتوسط & $y$ & الى حاث & نعم & & العبارات & r \\
\hline \multirow{2}{*}{ ૫ } & $r \varepsilon$ & $1 T \varepsilon$ & ITr & العدد & \multirow{2}{*}{ تساعدعاركة المجية الثعبةر للثبابات } & \multirow{2}{*}{1} \\
\hline & $11, r$ & $\varepsilon \varepsilon, V$ & $\varepsilon \varepsilon$ & $\%$ & & \\
\hline \multirow{2}{*}{$\Lambda r, v$} & $r \wedge$ & rA & $r T \leq$ & العدد & \multirow{2}{*}{ مشاعر الانتماء والولاء الوطني والدية تعليني } & \multirow{2}{*}{ r } \\
\hline & $I Y, V$ & $9, r$ & $\mathrm{VA}$ & $\%$ & & \\
\hline \multirow{2}{*}{ or } & $1 \cdot \varepsilon$ & $\Lambda$. & 117 & العدد & \multirow{2}{*}{ المشاركة المجتمعية للثباب تشاعد ألمتئ } & \multirow{2}{*}{$r$} \\
\hline & $r \varepsilon, V$ & $r 7, V$ & $r \wedge, \nu$ & $\%$ & & \\
\hline \multirow{2}{*}{ Or, r } & 97 & $9 \leq$ & 11. & العدد & \multirow{2}{*}{ للشباب ان يعبر عن نفسه وطاقدة المقاته } & \multirow{2}{*}{$\varepsilon$} \\
\hline & rr & $r, r$ & $r q, V$ & $\%$ & & \\
\hline \multirow{2}{*}{$V \varepsilon, \varepsilon$} & $\varepsilon \Lambda$ & 01 & 195 & العدد & \multirow{2}{*}{ التشبير عن قدراتهية للثبى العمل تحقق } & \multirow[b]{2}{*}{0} \\
\hline & 17 & $19, r$ & $T \varepsilon, V$ & $\%$ & & \\
\hline \multirow{2}{*}{11} & 17 & $\Lambda T$ & $r \cdot r$ & العدد & \multirow{2}{*}{ في التعرف على مشكلات مجنمية للشباب تساعدم } & \multirow[b]{2}{*}{7} \\
\hline & $0, r$ & $r V, r$ & $T V, r$ & $\%$ & & \\
\hline \multirow{2}{*}{$V \cdot, \tau$} & $r$. & 117 & $10 \leqslant$ & العدد & \multirow{2}{*}{ 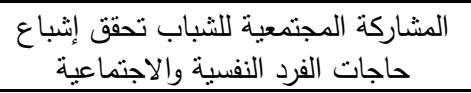 } & \multirow{2}{*}{ V } \\
\hline & 1. & $r \Lambda, \nu$ & $01, r$ & $\%$ & & \\
\hline \multirow{2}{*}{$07, \mathrm{~V}$} & 1. & $r \Lambda, \nu$ & $01, r$ & $\%$ & \multirow{2}{*}{ على المتساب مهارات وخبرات متعدددة } & \multirow{2}{*}{$\wedge$} \\
\hline & A. & $1 \ldots$ & $1 \%$. & العدد & & \\
\hline \multirow{2}{*}{$O V, V$} & $r \uparrow, V$ & $r \mu, r$ & $\varepsilon$. & $\%$ & \multirow{2}{*}{ على التخطيط وندبير حلول للمشيكلات في القدرة } & \multirow{2}{*}{9} \\
\hline & $\vee \wedge$ & 91 & $1 T \leq$ & العدد & & \\
\hline \multirow[b]{2}{*}{$\vee q, \varepsilon$} & YT & $r, v$ & $\Sigma 1, \Gamma$ & $\%$ & \multirow{2}{*}{ 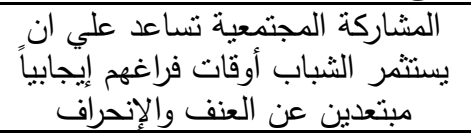 } & \multirow[b]{2}{*}{1.} \\
\hline & YT & $\Lambda$. & 191 & العدد & & \\
\hline
\end{tabular}

وصف الجدول:قام الباحث بأستخراج التكرارات والنسب المئوية والمتوسط المرجح المئوي لكل فقرات المقياس ويتبين من الجدول أن فقرة (المشاركة المجتمعية تعمل علي تقوية مشاعر

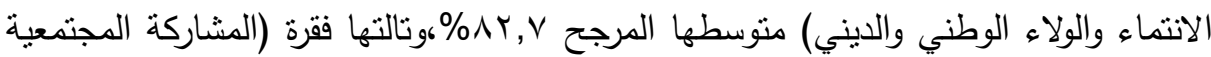

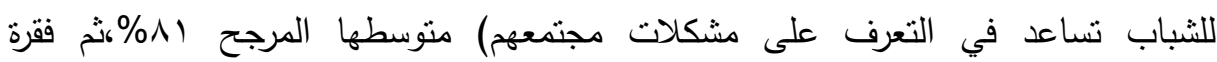

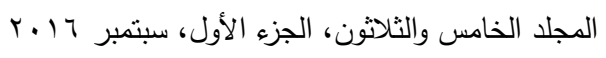


(المشاركة المجتمعية تساعد علي ان يستثمر الثباب أوقات فراغهم إيجابياً مبتعدين عن

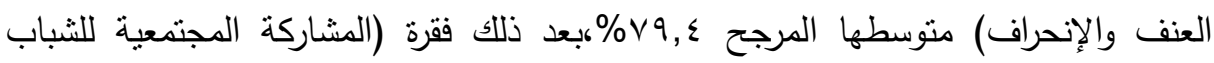

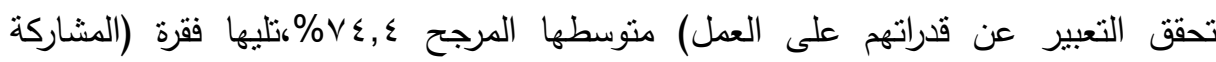
المجتمية للثباب تحقق إثباع حاجات الفرد النفسية والاجتماعية) منوسطها المرجح

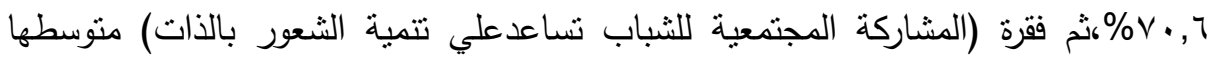
المرجح ع ,77\%،بعد ذلك فقرة (المشاركة المجتمعية تساعد في القدرة على التخطيط وتدبير

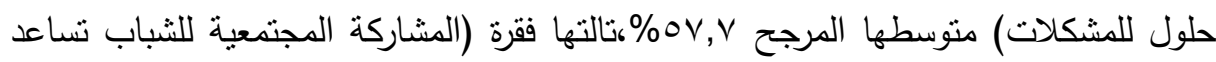

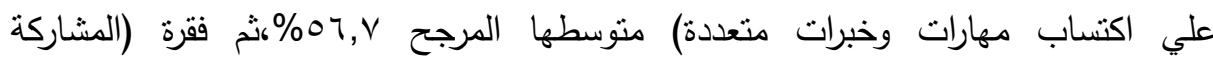

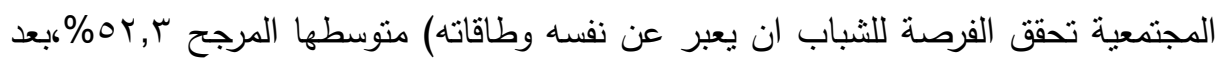
ذلك فقرة (المشاركة المجتمعية للثباب تساعد في توفير احتياجات المجتمع) متوسطها المرجح

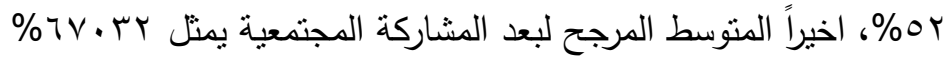
تفسير وتحليل الجدول: يتضح من الجدول السابق أن عبارات (المشاركة المجتمعية تعمل بهل علي تقوية مشاعر الانتماء والولاء الوطني والديني،المشاركة المجتمعية للشباب تساعد في

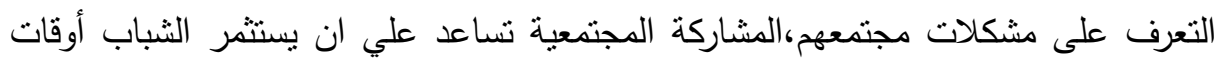

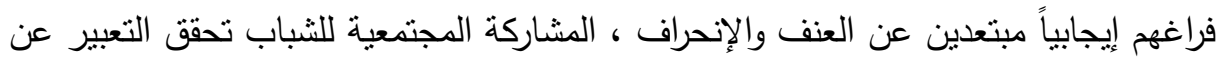
قدراتهم على العمل، المشاركة الدجمعية للشباب تحقق إثباع حاجات الفرد النفسية والاجتماعية) نسبتها تتخطي •v\% وهذا يضهر أن نسبة المشاركة جيدة جدا،بينما تظهرالمشاركة ودورها في المجتمع في البداية جيدة في فقرة (المشاركة المجتمعية للثباب

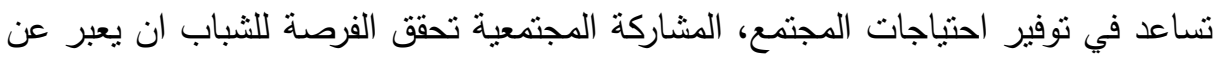
نفسه وطاقاته) بنسب .0\%،وتزداد نسبة المشاركة عند فقرات (المشاركة المجتمعية للثباب

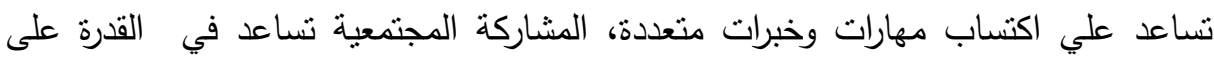

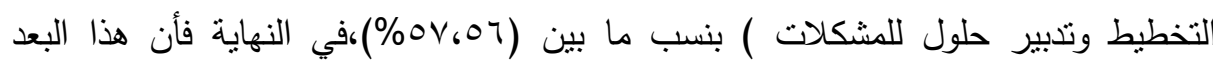

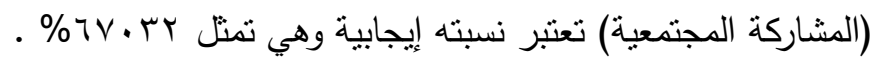


التساؤل الثاني: كيف تؤثر المعتقات الثعبية الإيجابية في تنمية مجتمع

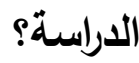

جدول(r): المشاركة الثبابية في مجال حماية البيئة

\begin{tabular}{|c|c|c|c|c|c|c|}
\hline المتوسط & $y$ & الي مدا & نعم & & العبارات & p \\
\hline \multirow{2}{*}{ Vo } & r & $\vee \wedge$ & 114 & العدد & \multirow{2}{*}{ ارغب المشاركة في الحفاظ على التلو البئي } & \multirow{2}{*}{1} \\
\hline & ir & rT & $7 r$ & $\%$ & & \\
\hline \multirow{2}{*}{$\Lambda 0, r$} & 11 & or & rr. & 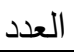 & \multirow{2}{*}{ ارغخ المشاركة في التوعية } & \multirow{2}{*}{ r } \\
\hline & 7 & $I V, r$ & $V \Psi, V$ & $\%$ & & \\
\hline \multirow{2}{*}{$\varepsilon q, r$} & 1.7 & 94 & $1 . r$ & العدد العد & \multirow{2}{*}{ ارغب المشاركة في العناية } & \multirow{2}{*}{$r$} \\
\hline & $r 0, r$ & $r \cdot, V$ & $\Gamma \varepsilon$ & $\%$ & & \\
\hline \multirow{2}{*}{$T V, T$} & $0 \leqslant$ & $\wedge 7$ & 17. & العدد & \multirow{2}{*}{ التعدي بالبناء علي الاركة في مقاومة } & \multirow{2}{*}{$\varepsilon$} \\
\hline & 11 & $r \wedge, \vee$ & r., & $\%$ & & \\
\hline \multirow{2}{*}{ (1) } & r & $v \cdot$ & $r \cdot \Lambda$ & العدد & \multirow{2}{*}{ ارغب المشاركة في العناية } & \multirow{2}{*}{0} \\
\hline & $v, r$ & r & $79, r$ & $\%$ & & \\
\hline \multicolumn{5}{|c|}{$\% \vee 1,7$} & \multicolumn{2}{|c|}{ المشاركة في المجال البيئي } \\
\hline
\end{tabular}

وصف الجدول: قام الباحث باستخراج التكرارات والنسب المئوية والمنوسط المرجح المئوي لكل فقرات المقياس وينتين من الجدول أن فقرة (ارغب المشاركة في الحفاظ على مكافحة التلوث

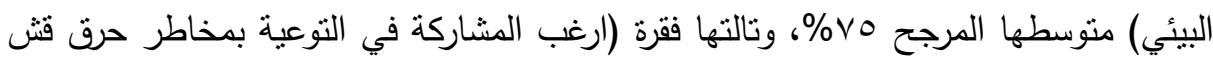

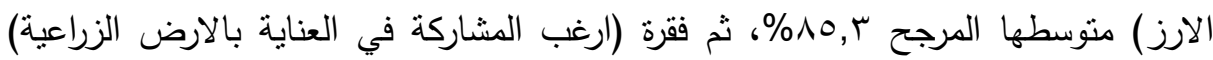
متوسطها المرجح ؟,9؛\%؛ بعد ذلك فقرة (ارغب المشاركة في مقاومة التعدي بالبناء علي

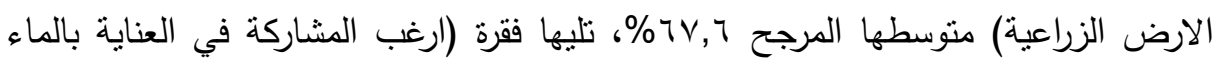

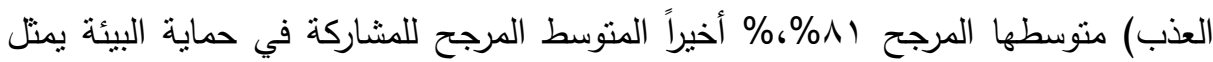
\% $\% 1,7 \varepsilon$ 
تفسير وتحليل الجدول: يتضح من الجدول السابق أن معظم أفراد العينة نتائجهم أيجابية في

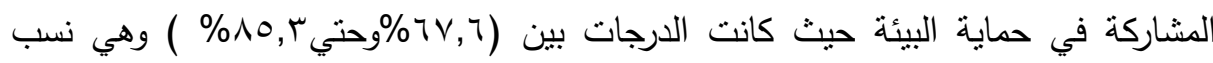
أيجابية، وهذا يتفق مع النسبة النهائية للمشاركة في الحفاظ علي البيئة والبيئية وهي .$(\% \vee 1,7)$

التساؤل الثالث: ما الإجراءات والمقترحات التي يمكن استخدامها لتشجيع ونشر ثقافة المشاركة المجتمعية لاى الشباب في قرية الدراسة؟ جدول(ץ): التحديات التي تواجه نشر ثقافة المشاركة المجتمعية

\begin{tabular}{|c|c|c|c|c|c|c|}
\hline المرجح & ע & الي حـا & نعم & & 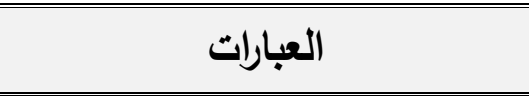 & \\
\hline \multirow{2}{*}{$r \leqslant, \varepsilon$} & $1 \wedge \varepsilon$ & NT & $r$. & العدد & \multirow{2}{*}{ من"العيب" بسبب الثباب من المشار نقارة العيبة } & \multirow{2}{*}{1} \\
\hline & $71, r$ & $Y \wedge, V$ & 1. & $\%$ & & \\
\hline \multirow{2}{*}{$r \uparrow, \varepsilon$} & IVY & 91 & $r$. & العدد & \multirow{2}{*}{ هل يعزف الثباب عن الفشل؟ المشاركة بسبب } & \multirow[b]{2}{*}{ r } \\
\hline & $\Delta V, r$ & rr,V & 1 . & $\%$ & & \\
\hline \multirow{2}{*}{$Y \wedge, V$} & 177 & 97 & rᄉ & العدد & \multirow{2}{*}{ التطوعي يقدر الثباب طبيعة المجتم الملحة له؟ } & \multirow{2}{*}{$r$} \\
\hline & $00, r$ & rt & $I Y, V$ & $\%$ & & \\
\hline \multirow{2}{*}{$r r, V$} & $10 \xi$ & 97 & 0. & العدد & \multirow{2}{*}{ 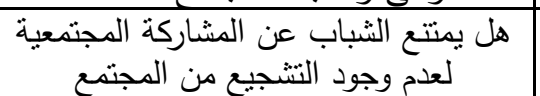 } & \multirow{2}{*}{$\varepsilon$} \\
\hline & $01, \pi$ & $\overline{r r}$ & $17, V$ & $\%$ & & \\
\hline \multirow{2}{*}{$r_{1, V}$} & Y. & 0. & $\varepsilon$. & 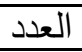 & \multirow{2}{*}{ هل يوجد برامج ثابتة لرعاية المنطوعين } & \multirow{2}{*}{0} \\
\hline & $V$. & $17, V$ & $T \Gamma, \Gamma$ & $\%$ & & \\
\hline \multirow{2}{*}{$\varepsilon r$} & Ir. & $1 \cdot 1$ & VY & 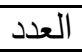 & \multirow{2}{*}{ هل يملثل وقت المشاركبة ألمجتمعية؟ دورا في } & \multirow{2}{*}{7} \\
\hline & $\xi$. & rq & $T \xi$ & $\%$ & & \\
\hline \multirow{2}{*}{$07, \mathrm{~V}$} & A. & $1 \cdots$ & IY. & 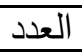 & \multirow{2}{*}{ هل كثرة التعقيدات البيرة الموقتمبية تؤثبث } & \multirow{2}{*}{ V } \\
\hline & $r \uparrow, V$ & r r & $\varepsilon$. & $\%$ & & \\
\hline$\%$ & & & & & 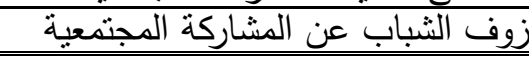 & \\
\hline
\end{tabular}

وصف الجدول: قام الباحث باستخراج التكرارات والنسب المئوية والمتوسط المرجح المئوي لكل فقرات المقياس وينتين من الجدول أن فقرة (هل يخاف الثباب من المشاركة من"العيب" بسبب التبراب

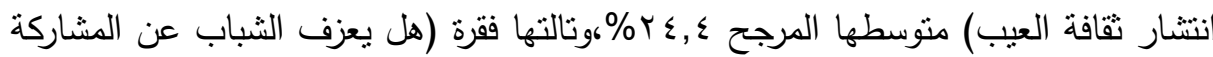

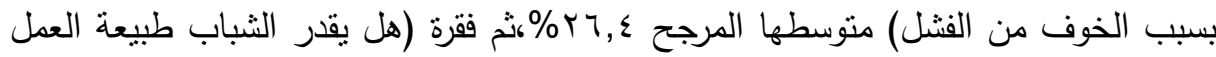

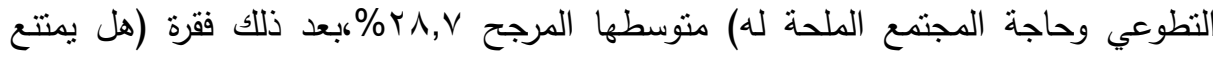
الثباب عن المشاركة المجتمعية لعدم وجود التحفيز والتشجيع من المجتمع) متوسطها المرجح 


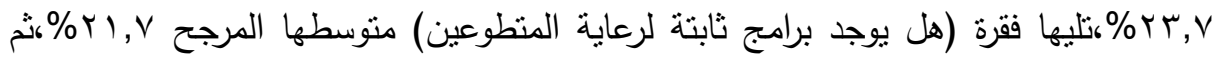
فقرة (هل يمثل وقت الثباب دورا مهما في عملية المشاركة المجتمعية) متوسطها المرجح r₹\%بعد ذلك فقرة (هل كثرة التعقيدات البيروقراطية تؤثر في عملية المشاركة المجتمعية)

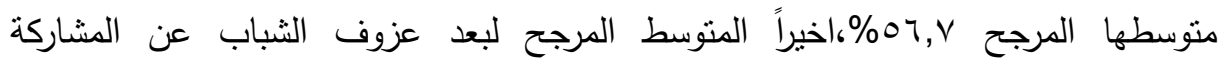

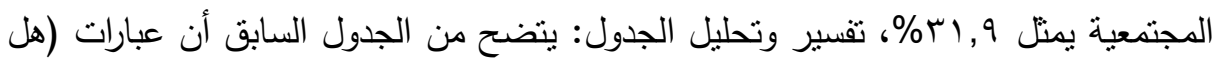

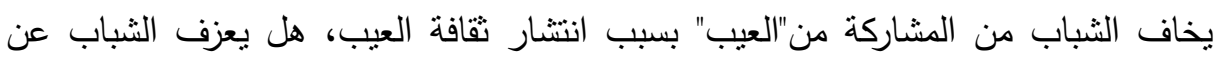

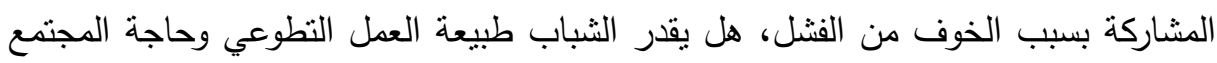

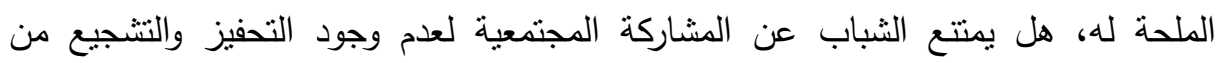

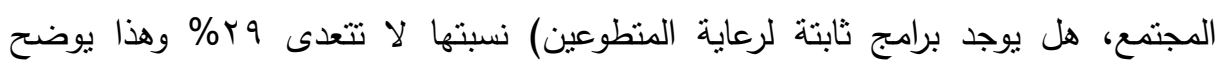

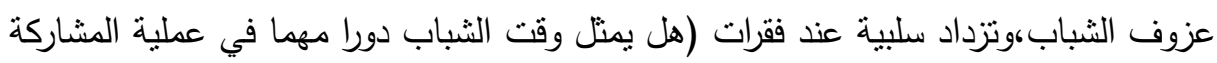

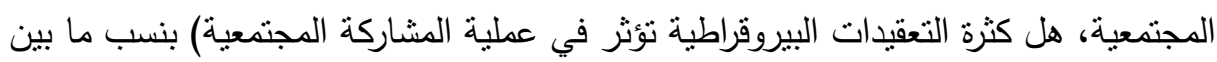

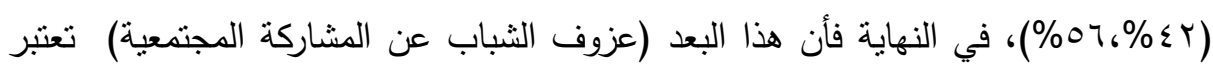

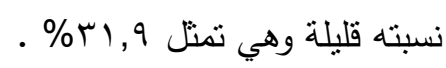

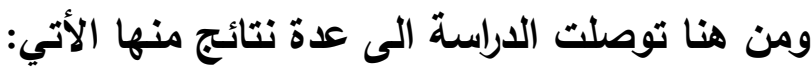

1- أوضحت نتائج الدراسة ان المشاركة المجتمعية نساعد علي نتمية الثعور بالذات، وتقوية مشاعر الاتتماء، والتعرف علي مشكلات المجتمع، واستثمار وقت الفراغ، والقدرة علي

$$
\text { التخطيط، وتساعد في توفير احتياجات المجتمع. }
$$

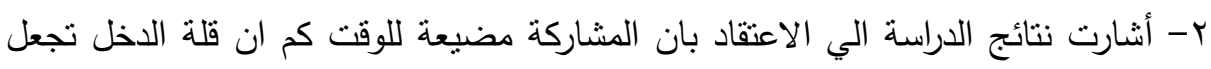

$$
\text { الثباب ينصرف الي تامين حاجتهم الاساسية. }
$$

r- أوضحت نتائج الدراسة دور الثباب القروي في محو الامية والمشاركة في الكوارث الأبنة الطبيعية واطفاء الحرائق وفي برامج العناية بالارض الزراعية ومقاومة التعدي عليها

والعناية بالماء العزب وحماية البيئة.

ع- اوضحت الدراسة ان المشاركة المجتمعية تشاعد علي تقوية شخصية الثباب واكسابهر خبرة في الحياة، وتتجيع التكافل الاجتماعي، ودعم التتمية البشرية في المجتمع.

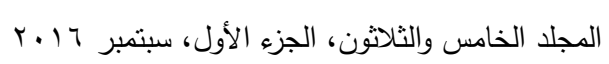




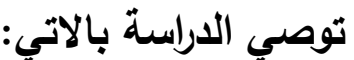

1- إعداد قاعدة بيانات أولية عن الشباب،فعلى ضوء رسم خريطة إحصائية دقيقة لخصائص وسمات الثباب المصري يمكن إعداد الخطط والسياسات بشكل يضمن استيعابه ضمن

$$
\text { الإطار المجتمعي. }
$$

r- ثقديم برامج إعلامية تهدف إلى التوعية السياسية للثباب، وأهمية المشاركة ومجالاتها وكيفية المشاركة الفاعلة.

r- تشجيع المشاركة المجتمعية في صفوف الثباب، مَهْهَا كان حَجْمه أو شَكْله أو نوعها. ع- تشجيع الثباب؛ وذلك بإيجاد مشاريع خاصة بهم تَهدف إلى تتمية رُوح الانتماء والمبادرة لََيَيهم. ه- أن ثُمارس المدرسة والجامعة والمؤسَّسة الدينية دورًا أكبرَ في حَثٌّ الثباب على المشاركة المجتمعية، خصوصًا في العُطلَ الصيفيَّة.

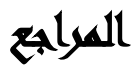

أحمد أبو زيد(911) (1): البناء الاجتماعي،المكتب الجامعي الحديث، الإسكندرية إسماعيل زكي(ب (911): الانثروبولوجيا والفكر الإنساني، عكاظ للنشر والتوزيع، جدة

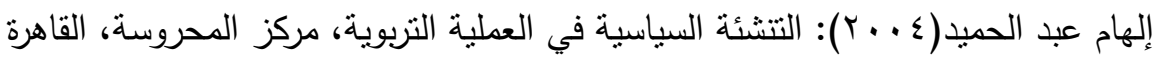
حكمت عرابي(1991 (): النظريات المعاصرة في علم الاجتماع| (99 19.

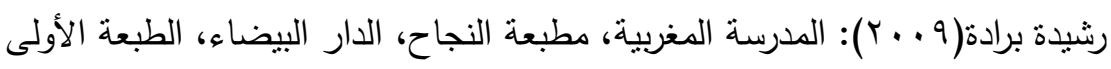

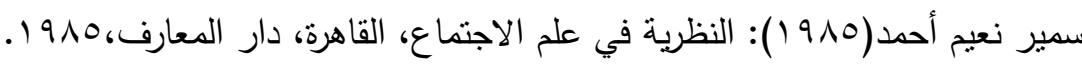
سيد يس(1997 ()): الوعي الثاريخي والثورة الكونية، مكتبة الانجلو، القاهرة عزت حجازي( •99 (19): الثباب العربي ومشكلاته، عالم المعرفة، الكويت ، ـ 199 ـ. على افرفار (997 (1)): صورة المرأة بين المنظور الديني والثعبي دار الطليعة، بيروت

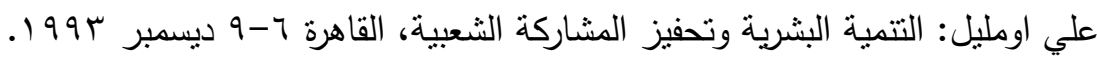


مصطفى إبراهيم عوض وآخرون

$$
\begin{aligned}
& \text { عمرو عبد الكريم(999 (199): " العولمة عالم ثالث على أبواب قرن جديد "، المنار } \\
& \text { تيماشيف نيقولا (97 } 99 \text { (): نظرية علم الاجتماع طبيعتها وتطورها، دار المعارف، القاهرة }
\end{aligned}
$$

Bourdieu Pierre, La jeunesse nest quun mots, in questions de sociologie, Minnuit, 1984.

Bourke, Lisa. 'Rural Communities.' Rurality Bites: The Social and Environmental Transformation of Rural Australia. Eds Stewart Lockie and Lisa Bourke. Sydney: Pluto Press, 2001. 118-128.

Brett, Judith (2007): The Country, the City and the State in the Australian Settlement.' Australian Journal of Political Science 42.1

Burnley, Ian, and Peter Murphy (2004): Sea Change: Movement from Metropolitan to Arcadian Australia. Sydney: UNSW P

Carter, David. (2006): Dispossession, Dreams and Diversity: Issues in Australian Studies. Sydney: Pearson Longman

'Social Class and Cultural Practice in Contemporary Australia.' Culture in Australia: Policies, Publics and Programs. Eds Tony Bennett and David Carter. Melbourne: Cambridge UP, 2001. 193-216.

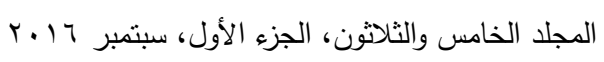


مجلة العلوم البيئية

معهذ الدراسات والبحوث البيئية - جامعة عين شمس البئ

\title{
RURAL FOLK CULTURE AND ITS ROLE IN ACTIVATING THE COMMUNITY PARTICIPATION FOR YOUNG PEOPLE IN A VILLAGE IN THE EASTERN PROVINCE
}

Awad, M. I. ${ }^{(1)}$; Abd El-Moneam, A. ${ }^{(2)}$ and Desouki, D. M.

1) Institute of Social Studies and Research, Ain Shams University.

2) League of Arab states

\begin{abstract}
The community participation of the most basic foundations for all the directions and strategies of development of effective, real serious development is not based only on the whole Jhodalmojtma, and I have taken the word community participation to spread widely among planners and administrators over the past decade and that the national and global levels, and focused on many of the folkloric studies studying the various elements of popular culture, where there is a severe scarcity of studies dealing with popular culture among young people in general, and the rural youth in particular, and here began the current study, which is trying to shed light on the relationship of popular culture youth of Egypt, and the extent of these young people influenced by culture and their association, and the vulnerability of those popular culture itself with these young people, and was chosen by the researchers on the theory of constructivism functional because they see the sociological designed to analyze and study the structures of society on the one hand and the functions of these structures on the other hand, this means that the structures did not exist at random because its functions will to conduct its investigation and in this sense, the social structures inevitable unavoidable is the presence of jobs have Thus for every social structure and function performed, since everything arbitrator will things go well in the community without a long wait for

$$
\text { المجلد الخامس والثلاثثن، الجزء الأول، سبتمبر } 17 \text {. }
$$
\end{abstract}


the conflicts and revolutions, society is a symphony of jobs are in harmony and balance, the study relied on a social survey sample through the "interview and questionnaire approach, was chosen as the sample through stratified sample (by age group) and then random sample amounted to a sample study of 300 young males and females, the study reached several conclusions, including, that community participation will help to develop a sense of self, and strengthen feelings of belonging, and become acquainted with the problems of society, and invest leisure time, and the ability to plan, and help provide for the needs of society, and study results indicated a belief that participation is a waste of time as the lack of income makes young people go out to secure the basic needs, the study recommends preparation of preliminary data for the young and the base fee, and provide media programs designed to educate young people Bahmam and where and how community participation actors statistically accurate map of the characteristics and attributes of youth. 